\title{
Arbitragem entre açúcar e etanol em usinas vendedoras de energia elétrica
}

\author{
Arbitrage between sugar and ethanol in electricity seller mills
}

\author{
André Luís da Silva Volpe ${ }^{*}$, Marta Cristina Marjotta-Maistro², Octávio Antonio Valsechi
}

\footnotetext{
1 Engenheiro Químico; Rua João Battaus, 111, Jardim Álvaro Brito - Cep: 15400-000 - Olímpia (SP), Brasil

2 Professor Adjunto, Departamento de Tecnologia Agroindustrial e Socioeconomia Rural do Centro de Ciências Agrárias da Universidade Federal de São Carlos - marjotta@cca.ufscar.br

3 Professor Associado, Departamento de Tecnologia Agroindustrial e Socioeconomia Rural do Centro de Ciências Agrárias da Universidade Federal de São Carlos - vico@ufscar.br
}

\section{Resumo}

Dado que a composição principal do portifólio atual de produtos do setor sucroenergético no Brasil envolve o açúcar, o etanol e a energia elétrica, o objetivo deste trabalho é analisar a influência da produção de energia elétrica na receita total da usina para cenários típicos, porém hipotéticos, de variação de mix de produção entre açúcar e etanol. Os principais dados técnicos para composição dos cenários foram retirados de trabalhos científicos relacionados com o setor sucroenergético e utilizados nas etapas de cálculo para modelagem dos cenários. Ao final do trabalho, identificou-se uma possível oportunidade de aumento da receita financeira a partir de mudanças no mix de produção e demonstrouse a importância de realizar a mesma análise para cálculos reais das operações de arbitragem no setor. Palavras-chave: cana- de-açúcar, cogeração, margem de lucro, sucroenergético

\begin{abstract}
Since the main composition of the current products portfolio in Brazilian sugarcane industry involves sugar, ethanol and electricity, the objective of this study is to analyze the influence of electricity production in the total revenue of the mill for typical scenarios, however hypotheticals, considering changes in the quantities between sugar and ethanol in the production mix. The main technical data used for the scenarios modeling were taken from scientific papers related with the sugarcane industry. At the end of this work, a possible opportunity for increasing the financial revenue by changing the production mix was identified and the importance of performing the same analysis in actual calculations of arbitrage operations in the sugarcane industry was demonstrated.

Keywords: cogeneration, profit margin, sugarcane industry, sugarcane
\end{abstract}

\section{Introdução}

A possibilidade de produção e armazenagem do açúcar e do etanol nas usinas resulta em uma conhecida peculiaridade desta agroindústria, que é a arbitragem entre estes dois produtos para alcançar o máximo resultado financeiro.

Nas últimas décadas, com a viabilização econômica da venda de energia elétrica de biomassa nas usinas, a energia elétrica assumiu um importante espaço dentre a gama de produtos do setor sucroenergético. Entre as inúmeras vantagens desta fonte pode-se atribuir: limpa e renovável, sazonal complementando a hídrica, grande potencial de expansão, baixo custo de produção se comparada à gerada por combustíveis fósseis, etc.

\footnotetext{
${ }^{1}$ Autor correspondente <andre.volpe@hotmail.com> Enviado: 11 ago. 2015 Aprovado: $10 \mathrm{dez} .2015$
} 
O bagaço da cana, bem como sua palha tem um bom valor como combustível e é utilizado para geração da energia necessária para operação da usina. As unidades industriais processadoras de cana-de-açúcar aproveitam o vapor produzido nas caldeiras para gerar energia elétrica em turbo-geradores, antes de utilizar o vapor no processo. A geração simultânea de vapor e energia para o processo produtivo é denominada cogeração (Venkatesh; Roy, 2010). Uma geração de energia mais eficiente poderia ser atingida com a instalação de sistemas de cogeração avançados nas usinas, utilizando caldeiras de alta pressão e turbinas à vapor de condensação (Premalatha et al., 2008).

Um aspecto importante da geração de energia elétrica nas biorrefinarias sucroenergéticas é que ela ocorre fortemente integrada à produção de açúcar e etanol. Por isso, criou-se o termo cogeração para descrever este processo.

Deste modo, a demanda de energia utilizada para a produção de açúcar e etanol influencia diretamente na quantidade de energia elétrica produzida. Esta demanda pode ser diferente entre o açúcar e o etanol, pois depende das tecnologias aplicadas para o processo de cada produto e das condições de conservação e operação dos equipamentos.

Ciente das diferenças entre as quantidades de energia demandadas por cada produto, pode-se realizar uma análise integrada do processo produtivo visando otimizar o resultado financeiro a partir da arbitragem entre o açúcar e o etanol, considerando o impacto na produção de energia elétrica.

O objetivo geral deste trabalho é realizar uma análise da influência da venda de energia elétrica nas unidades industriais processadoras de cana-de-açúcar objetivando determinar a melhor arbitragem entre o açúcar e o etanol visando alcançar a maior receita quando se considera estes três produtos, e mais especificamente, simular diferentes cenários de mix de produção para a configuração típica de uma biorrefinaria sucroenergética no Brasil.

\section{Material e métodos}

Para realização dos cálculos de balanço de massa e energia e elaboração dos cenários, foram utilizados dados encontrados na literatura, sendo Rein (2007), Seabra (2008), Hugot (1986), Ceballos-Schiavone (2009), Smith et. al. (2007), Dias (2008). No entanto, durante o processo produtivo podem existir várias possibilidades de configurações e interações entre as linhas de produção específicas de cada usina. Por isso, recomenda-se fortemente que, ao aplicar a análise para uma unidade industrial específica e conhecida, sejam consideradas todas as interações do processo de forma rigorosamente modelada através de um balanço de massa e energia. Após a modelagem será possível determinar com maior exatidão a variação do consumo de vapor total em relação aos cenários de mix de produção de açúcar e etanol. 
A metodologia para conversão de açúcar em açúcar redutor total - ART e etanol em ART foi adotada de acordo com Fernandes (2011).

Para cálculo do valor financeiro da venda de energia elétrica utilizaremos o valor médio do Preço de Liquidação das Diferenças - PLD predominante nos submercados no ano de 2015, de $\mathrm{R} \$ 388,48$ por MWh, de acordo com a Câmara de Comercialização de Energia Elétrica - CCEE (CCEE, 2015).

\section{Evaporação do caldo}

Para estimar o consumo de vapor nesta operação foi realizado um balanço de massa e energia de uma evaporação convencional de cinco efeitos com sangria de vapor no primeiro e segundo efeito, a partir da metodologia simplificada descrita por Rein (2007). Como premissas para elaboração dos cenários de consumo de vapor, para determinação das sangrias de vapor, adotou-se que a fábrica de açúcar utilizará vapor vegetal do segundo efeito da evaporação (S2) e a destilaria e aquecimento do caldo utilizará vapor vegetal do primeiro efeito da evaporação (S1).

De acordo com Seabra (2008), o caldo clarificado (14-16ºrix) segue para a concentração em evaporadores múltiplo-efeitos, dando origem ao xarope (com $60^{\circ}$ Brix). Portanto, neste trabalho, os cálculos foram feitos para 100 toneladas de sólidos solúveis diluídos à 16\% (em massa) no caldo clarificado e 60\% (em massa) no xarope.

\section{Aquecimento do caldo}

O consumo de vapor nesta etapa foi calculado através de balanço de massa e energia conforme descrito por Rein (2007) e Hugot (1986).

De acordo com Rein (2007), a quantidade de vapor consumida no aquecimento do caldo pode ser estimada através de um balanço de energia, conforme equação 1 :

$$
\mathrm{m}_{\mathrm{vapor}}=\frac{\mathrm{m}_{\text {caldo }} \times \mathrm{c} \times\left(\mathrm{T}_{\mathrm{s}}-\mathrm{T}_{\mathrm{e}}\right)}{\left(\Delta \mathrm{H}_{\mathrm{vapor}}\right)}
$$

Onde: $\mathrm{m}_{\text {vapor }}$ é a quantidade de vapor consumido, em toneladas; $\mathrm{m}_{\text {caldo }}$ é a quantidade de caldo aquecido, em toneladas; c = calor específico do caldo, em $\mathrm{kJ} / \mathrm{kg}^{\circ} \mathrm{C} ; \mathrm{T}_{\mathrm{s}}$ é temperatura de saída do caldo, em ${ }^{\circ} \mathrm{C} ; \mathrm{T}_{\mathrm{e}}$ é a temperatura de entrada do caldo, em ${ }^{\circ} \mathrm{C} ; \Delta \mathrm{H}_{\mathrm{vapor}}$ é a variação de entalpia do vapor, em $\mathrm{kJ} \mathrm{kg}^{-1}$.

De acordo com Hugot (1986), a equação 2 fornece uma boa aproximação do calor específico do caldo. 


$$
\mathrm{c}=4,187 \times\left(1-0,006 \times \text { Brix }_{\text {caldo }} \times 100\right)
$$

Onde:Brix ${ }_{\text {caldo }}$ é sólidos solúveis dissolvidos no caldo, em porcentagem

Portanto, como considerou os sólidos solúveis diluídos no caldo igual a $16 \%$ tem massa temos:

$$
\mathrm{c}=4,187 \times(1-0,006 \times 16)=3,785 \mathrm{~kJ} /\left(\mathrm{kg}{ }^{\circ} \mathrm{C}\right)
$$

De acordo com Ceballos-Schiavone (2009), o caldo enviado para o aquecimento tem sua temperatura elevada à $102-105^{\circ} \mathrm{C}$, afim de promover a floculação dos coloides com maior rapidez e facilidade. A temperatura limite de $105^{\circ} \mathrm{C}$ é adotada, pois, quando ultrapassada, existe a possibilidade das ceras presentes no caldo emulsificarem tornando difícil sua separação, enquanto que temperaturas do caldo aquecido abaixo de $98{ }^{\circ} \mathrm{C}$ diminuem a eficiência da clarificação.

Geralmente, não é economicamente viável projetar o aquecimento do caldo de forma que a diferença entre a temperatura do caldo na saída do aquecedor e a temperatura do condensado do vapor seja inferior a $10^{\circ} \mathrm{C}$. Como a temperatura do vapor vegetal do primeiro efeito é levemente acima de $110^{\circ} \mathrm{C}$, o aquecimento com o vapor vegetal do primeiro efeito já é suficiente para levar o caldo próximo à temperatura adequada sem necessidade de utilizar vapor de escape (Rein, 2007).

Dessa forma, a Tabela 1 apresenta os valores assumidos para o cálculo do consumo de vapor no aquecimento do caldo. Os valores de entalpia foram obtidos das tabelas de vapor disponibilizadas por Smith et al. (2007).

Logo, para elaboração dos cenários de consumo de vapor, assume um consumo de 74,3 toneladas de vapor vegetal do primeiro efeito da evaporação para aquecimento do caldo. 
Tabela 1. Dados para o cálculo do consumo de vapor para aquecimento do caldo

\begin{tabular}{ll}
\hline Características do vapor vegetal do primeiro efeito & \\
\hline Temperatura do vapor vegetal V1 & $110^{\circ} \mathrm{C}$ \\
Estado do vapor: saturado & \\
Entalpia do vapor & $2691,3 \mathrm{~kJ} \mathrm{~kg}^{-1}$ \\
Entalpia do condensado & $461,3 \mathrm{~kJ} \mathrm{~kg}^{-1}$ \\
\hline Características do caldo & \\
\hline Quantidade de caldo & 625 toneladas \\
temperatura de entrada do caldo (ambiente) & $30^{\circ} \mathrm{C}$ \\
temperatura de saída do caldo & $100^{\circ} \mathrm{C}$ \\
\hline
\end{tabular}

Fonte: Smith et al., 2007

$$
\text { Portanto, } \mathrm{m}_{\mathrm{vapor}}=\frac{635 \times 3,785 \times(100-30)}{(2961,3-461,3)}=74,3 \text { toneladas }
$$

Consumo de vapor da fábrica de açúcar

De acordo com Rein (2007), é possível calcular a quantidade de água evaporada nos cozedores através de um balanço de massa do cozimento. Porém, água é adicionada nas centrífugas, tanques e diluidores, e toda esta água precisa ser evaporada. Uma parte do vapor também é usada nas centrífugas e no secador de açúcar. É uma prática comum aplicar um "fator do cozimento" ao consumo de vapor necessário para a evaporação nos cozedores para considerar estas necessidades de evaporação adicionais. Rein (2007) estimou em 0,898 kg de vapor por cada $\mathrm{kg}$ de sólidos solúveis no xarope como a quantidade de vapor vegetal utilizada na fábrica de açúcar considerando um cozimento típico de duas massas.

Recuperação da fábrica

A recuperação da fábrica consiste na quantidade de sacarose que foi cristalizada, recuperada e produzida em relação a toda sacarose que foi alimentada na fábrica com o xarope (Equações 3 e 4).

$$
\text { Recuperação da fábrica }(\%)=\frac{\left(\mathrm{m}_{\text {xarope }} \times \mathrm{P}_{\text {xarope }}\right)-\left(\mathrm{m}_{\text {melaço }} \times \mathrm{P}_{\text {melaço }}\right)}{\left(\mathrm{m}_{\text {xarope }} \times \mathrm{P}_{\text {xarope }}\right)}
$$

$\mathrm{Ou}$,

$$
\text { Recuperação da fábrica }(\%)=\frac{\left(\mathrm{m}_{\text {açúcar }} \times \mathrm{P}_{\text {açúcar }}\right)}{\left(\mathrm{m}_{\text {xarope }} \times \mathrm{P}_{\mathrm{xarope}}\right)}
$$


Onde, $\mathrm{m}_{\mathrm{i}}$ é a massa da corrente $\mathrm{i} ; \mathrm{P}_{\mathrm{i}}$ é a pureza da corrente $\mathrm{i}$

No Brasil pode-se encontrar frequentemente melaço sendo produzido com pureza até $55 \%$. Neste caso, das 85 toneladas de sacarose presente no xarope, 18,5 toneladas ainda restariam no melaço que, com $55 \%$ de pureza, representaria uma quantidade de 33,5 toneladas de melaço.

Pode-se então calcular a recuperação da fábrica com o melaço de 55\% de pureza:

$$
\text { Recuperação da fábrica (\%) }=\frac{100 \times 85 \%-33,5 \times 55 \%}{100 \times 85 \%} \cong 78 \%
$$

$\mathrm{Ou}$,

$$
\text { Recuperação da fábrica }(\%)=\frac{66,5 \times 99,3 \%}{100 \times 85 \%} \cong 78 \%
$$

Para elaboração dos cenários de consumo de vapor, adotou uma recuperação da fábrica de açúcar de $78 \%$, tipicamente encontrada nas usinas brasileiras.

Consumo de vapor para produção de etanol

O consumo de vapor para produção de etanol na etapa de destilação foi estimado de acordo com Dias (2008) que realizou simulações adotando uma pressão do vapor para produção de etanol hidratado de 2,5 bar (vapor de escape). O consumo de vapor (2,5 bar) obtido para a produção de etanol hidratado foi de 1,80 kg vapor/L etanol utilizando-se a tecnologia de destilação convencional.

Tais consumos foram obtidos no simulador em condições ótimas de operação, porém Dias (2008) também indica que o processo de destilação total entre etanol hidratado e etanol anidro utilizando-se a destilação azeotrópica com cicloexano pode chegar a consumir até 4,2 $\mathrm{kg}$ vapor/L etanol e que a destilação azeotrópica com cicloexano, sozinha, é responsável pelo consumo de 1,5 a 1,6 kg de vapor/L de etanol. Ou seja, descontando a parcela de 1,5 kg de vapor/L de etanol referente à destilação com cicloexano, pode-se encontrar consumos de vapor para produção de etanol hidratado de aproximadamente $2,7 \mathrm{~kg}$ vapor/L etanol.

Portanto, realizou uma média simples entre os consumos de 1,8 e 2,7 kg vapor/L de etanol, assumiu-se um consumo de vapor médio na etapa de destilação de 2,25 kg vapor/L etanol hidratado, utilizando o vapor vegetal do primeiro efeito da evaporação. 
A produção de etanol anidro não foi avaliada neste trabalho, consistindo de uma variação deste estudo com a adição do consumo de vapor para desidratação do etanol hidratado para etanol anidro.

\section{Eficiência de geração de energia elétrica}

A eficiência de geração de energia elétrica foi calculada de acordo com (Smith et al, 2007).

No caso das unidades industriais produtoras de açúcar e etanol, o vapor que sai da turbina, chamado de vapor de escape, sendo utilizado no primeiro estágio da evaporação do caldo e algumas vezes nos aparelhos de destilação de etanol. No contexto do setor sucroalcooleiro, a pressão do vapor de escape varia entre 2,0 a 2,5 bar, em pressão absoluta, e normalmente são encontradas pressões do vapor de entrada da turbina de 22 bar, 44 bar, 63 a 67 bar e até pressões de 100 bar.

Considerando uma tonelada de vapor 67 bar e 525을 fornecido ao turbogerador, a quantidade de energia gerada pode ser calculada pela equação 5 (Smith et al, 2007).

$$
\mathrm{W}=\frac{\eta \times \mathrm{m} \times\left(\mathrm{H}_{2}-\mathrm{H}_{1}\right)_{\text {isentrópico }}}{3600}
$$

Onde: $\mathrm{W}$ é a potência gerada no turbogerador, em $\mathrm{kW} ; \eta$ é a eficiência da turbina; $\mathrm{m}$ é a vazão mássica de vapor, em $\mathrm{kg} / \mathrm{h} ; \mathrm{H}_{2}$ é a entalpia do vapor na saída da turbina, em kJ/kg; $\mathrm{H}_{1}$ é a entalpia do vapor na entrada da turbina, em $\mathrm{kJ} / \mathrm{kg}$.

De acordo com Smith et al. (2007), se o fluido no interior da turbina se expande reversivelmente e adiabaticamente, o processo é isentrópico, e a entropia no estado final (saída) é igual à entropia no estado inicial (entrada). Esta consideração fixa o estado final do fluido e possibilita a determinação da entalpia na saída da turbina. A condição isentrópica representa o máximo de energia que pode ser obtido de uma turbina adiabática com condições de entrada especificadas juntamente com a pressão na descarga. Turbinas reais produzem menos energia, pois o processo de expansão real é irreversível. Os valores de eficiência da turbina estão na faixa de 0,7 a 0,8.

Neste trabalho adotou um valor intermediário de 0,75 para a eficiência da turbina, logo, $\eta=0,75$.

Portanto, utilizando a equação 5 e os dados da Tabela 2, pode-se calcular a geração de energia elétrica para cada $1000 \mathrm{~kg}$ de vapor utilizado na turbina de contrapressão: 
Tabela 2. Dados utilizados para cálculo da geração de energia

\begin{tabular}{|c|c|c|c|}
\hline & \multicolumn{3}{|c|}{ Geração de energia por contrapressão } \\
\hline & Entrada & Saída (isentrópico) & Saída (real) \\
\hline Pressão (bar) & 67,0 & 2,5 & 2,5 \\
\hline Temperatura $\left({ }^{\circ} \mathrm{C}\right)$ & 525 & 127 & 212 \\
\hline Entalpia (kJ/kg) & 3.473 & 2.655 & 2.860 \\
\hline \multirow[t]{3}{*}{ Entropia $\left(\mathrm{kJ} / \mathrm{kg}^{\circ} \mathrm{C}\right)$} & 6,8985 & 6,8985 & 7,3366 \\
\hline & \multicolumn{3}{|c|}{ Geração de energia por condensação } \\
\hline & Entrada & Saída (isentrópico) & Saída (real) \\
\hline Pressão (bar) & 67,0 & 0,3 & 0,3 \\
\hline Temperatura $\left({ }^{\circ} \mathrm{C}\right)$ & 525 & 69 & 157 \\
\hline Entalpia (kJ/kg) & 3.473 & 2.327 & 2.614 \\
\hline Entropia $\left(\mathrm{kJ} / \mathrm{kg}^{\circ} \mathrm{C}\right)$ & 6,8985 & 6,8985 & 7,6163 \\
\hline
\end{tabular}

Fonte: Smith et al., 2007

$$
\mathrm{W}=\frac{0,75 \times 1000 \times(3473-2655)}{3600}=170,4 \mathrm{~kW}
$$

E para cada $1000 \mathrm{~kg}$ de vapor utilizado na turbina de condensação:

$$
\mathrm{W}=\frac{0,75 \times 1000 \times(3473-2327)}{3600}=238,8 \mathrm{~kW}
$$

Assim, pode-se calcular a eficiência de geração de energia, definida como sendo a quantidade de energia gerada em MWh por tonelada de vapor fornecido para a turbina. $A$ partir das premissas utilizadas, a eficiência de geração de energia por contrapressão é de $0,17 \mathrm{MWh} /$ tonelada de vapor e a eficiência de geração de energia por condensação é 0,24 $\mathrm{MWh} /$ tonelada de vapor.

A geração de energia por condensação pode ser realizada mesmo durante a entressafra utilizando um estoque de bagaço produzido durante a safra ou então comprando bagaço de outras usinas ou outros tipos de biomassa, como a palha de cana e cavaco de madeira (Venkatesh; Roy, 2010). Por isso, um aumento no consumo de vapor da usina durante a safra, e consequentemente aumento no consumo de biomassa, diminui a quantidade de biomassa disponível para geração de energia em condensação.

\section{Resultados e Discussão}

Realizou-se algumas simulações de balanço de massa e energia variando o mix de produção entre açúcar e etanol, observando as variações no consumo de vapor de escape do processo e na venda de energia. Adotou-se uma escala de variação de 5 pontos percentuais 
no mix de produção para cada cenário, resultando em 10 simulações que estão apresentadas no Anexo 1. A Tabela 3 apresenta um resumo dos resultados obtidos.

O ART total produzido (Tabela 3 ) varia entre os cenários avaliados por causa do desconto atribuído a eficiência da fermentação conforme a quantidade de caldo para etanol é ajustada pelo mix de produção.

Observou-se, a partir da Tabela 3, que o consumo de vapor aumenta conforme o mix de produção para açúcar aumenta e, consequentemente, ocorre uma diminuição da receita devido à diminuição da venda de energia elétrica. Notou-se um incremento de aproximadamente $\mathrm{R} \$ 1,50 / \mathrm{t}$ ART produzido para cada aumento de 5 pontos percentuais no mix de produção, que poderia ser avaliado com um custo de oportunidade de venda de energia elétrica.

Tabela 3. Comparação do consumo de vapor, venda de energia e variação na receita para os cenários de mix de produção de açúcar para diferentes porcentagens.

\begin{tabular}{|c|c|c|c|c|c|c|}
\hline Cenário & $\begin{array}{c}\text { Mix de } \\
\text { produção } \\
\text { para açúcar }\end{array}$ & $\begin{array}{l}\text { Consumo } \\
\text { de vapor de } \\
\text { escape }\end{array}$ & $\begin{array}{l}\text { 1ART total } \\
\text { produzido }\end{array}$ & $\begin{array}{l}\text { Diminuição da } \\
\text { venda de } \\
\text { energia }\end{array}$ & $\begin{array}{l}\text { Diminuição } \\
\text { da receita }\end{array}$ & ART \\
\hline & $\%$ & & & MWh & $\mathrm{R} \$$ & $R \$ t^{-1}$ \\
\hline 1 & 35,0 & n.a. ${ }^{2}$ & n.a. & n.a. & n.a. & n.a. \\
\hline 2 & 40,0 & n.a. & n.a. & n.a. & n.a. & n.a. \\
\hline 3 & 45,0 & 195,3 & 83,8 & 0,0 & 0,0 & 0,0 \\
\hline 4 & 50,0 & 199,9 & 84,3 & 0,3 & 124,1 & 1,5 \\
\hline 5 & 55,0 & 204,5 & 84,8 & 0,6 & 249,6 & 2,9 \\
\hline 6 & 60,0 & 209,2 & 85,3 & 1,0 & 376,7 & 4,4 \\
\hline 7 & 65,0 & 213,9 & 85,8 & 1,3 & 505,2 & 5,9 \\
\hline 8 & 70,0 & 218,7 & 86,3 & 1,6 & 635,3 & 7,4 \\
\hline 9 & 75,0 & 223,5 & 86,8 & 2,0 & 766,9 & 8,8 \\
\hline 10 & 78,9 & 227,4 & 87,2 & 2,2 & 871,1 & 10,0 \\
\hline
\end{tabular}

${ }^{1}$ ART: açúcar redutor total, ${ }^{2}$ n.a.: não aplicável

No Anexo 1, nos cenários 1 e 2, a simulação retornou valores negativos de vazões de vapor vegetal na evaporação. Isto indica que a quantidade de caldo enviada para a evaporação não possui água suficiente para ser evaporada e atender as demandas de vapor vegetal requeridas na simulação. Neste caso, para a usina operar com um mix de produção inferior a $40 \%$ será necessário rever a configuração do processo. Por exemplo, instalando um evaporador no caldo enviado à destilaria para aumentar a geração de vapor vegetal. 
Neste trabalho, manteve-se a configuração do processo estabelecida a partir das premissas adotadas anteriormente e, portanto, desconsiderou-se os cenários 1 e 2 e ainda qualquer cenário com mix de produção para açúcar igual ou inferior a 40\%. Assim, o cenário 3 foi adotado como base de comparação para os outros cenários.

O cenário 10 representa a simulação com o mix de produção para açúcar máximo (78,9\%), em que todo o caldo é enviado para a evaporação e, em seguida, para a fábrica de açúcar. Neste cenário, a produção de etanol é proveniente apenas do mel final. A partir deste ponto, a única opção para aumentar o mix para açúcar é aumentando a recuperação da fábrica, substituindo a configuração de duas massas para uma fábrica de três massas, por exemplo.

Novamente, manteve-se a configuração do processo estabelecida a partir das premissas adotadas anteriormente, ou seja, adotou-se uma fábrica de duas massas. Logo, o cenário 10 representa o mix de produção máximo para açúcar.

O resultado deste trabalho foi obtido a partir das premissas adotadas, citadas anteriormente. $\mathrm{Na}$ ocasião da aplicação desta análise para um caso real pode ser necessário rever as premissas para o caso estudado. De qualquer modo, o resultado obtido indica que a venda de energia elétrica é um fator a ser avaliado em um estudo de arbitragem entre açúcar e etanol nas usinas de cana-de-açúcar que possue venda de energia. A Tabela 4 resume o resultado deste trabalho apresentando o aumento de receita por tonelada de ART para cada cenário de mix de produção.

Tabela 4. Aumento de receita por tonelada de Açúcares Redutores Totais [ART] para cada cenário de mix de produção

\begin{tabular}{cccc}
\hline Cenário & $\begin{array}{c}\text { Mix de } \\
\text { produção } \\
\text { para açúcar }\end{array}$ & $\begin{array}{c}\text { ART } \\
\text { acumulado }\end{array}$ & $\begin{array}{c}\text { ART por } \\
\text { cenário }\end{array}$ \\
\hline & $\%$ & & $\mathrm{R} \$ \mathrm{t}^{-1}$ \\
1 & 35,0 & n.a. & n.a. \\
2 & 40,0 & n.a. & n.a. \\
3 & 45,0 & 0,00 & 0,00 \\
4 & 50,0 & 1,5 & 1,5 \\
5 & 55,0 & 2,9 & 1,5 \\
6 & 60,0 & 4,4 & 1,5 \\
7 & 65,0 & 5,9 & 1,5 \\
8 & 70,0 & 7,4 & 1,5 \\
9 & 75,0 & 8,8 & 1,5 \\
10 & 78,9 & 10,0 & 1,2 \\
\hline
\end{tabular}




\section{Conclusão}

Com este estudo foi possível observar a importância de considerar o impacto obtido com a venda de energia elétrica durante a análise de arbitragem entre o açúcar e o etanol, dado que foi identificado, a partir das simulações realizadas, apresentando uma variação da receita de $R \$ 1,50$ por tonelada de ART produzido devido à variação da venda de energia elétrica para cada variação de 5 pontos porcentuais no mix de produção nos cenários simulados. Ou seja, uma decisão para se produzir mais açúcar ou mais etanol sem considerar o impacto no consumo de vapor do processo, e assim na comercialização de energia elétrica, pode levar a uma margem de lucro menor que a esperada pela unidade industrial, quando se considera os três produtos. Além disso, o estudo destaca a importância da investigação e controle dos parâmetros de processo no setor sucroenergético, pois são fundamentais para uma boa qualidade das análises financeiras e aproveitamento eficaz das oportunidades nas operações comerciais. A aplicação do presente estudo para um caso real, se faz necessário rever os parâmetros técnicos adotados no modelo para o caso específico a ser estudado, pois pode haver grandes variações dependendo do processo de cada unidade industrial.

\section{Referências}

Câmera de Comercialização de Energia Elétrica [CCEE]. 2015. Preços Médios. Disponível em: <http://www.ccee.org.br/portal/faces/pages_publico/o-que-

fazemos/como_ccee_atua/precos/precos_medios?_afrLoop $=564694816530864 \# \% 40 \% 3 \mathrm{~F}$ a frLoop\%3D564694816530864\%26_adf.ctrl-state\%3Dky7vrcryv_58>. Acesso em 21/05/2015.

Ceballos-Schiavone, C.H.M. 2009. Tratamento térmico do caldo de cana-de-açúcar visando a redução de contaminantes bacterianos - Lactobacillus - na produção de etanol e eficiência de tratamento do fermento por etanol. 177p. Dissertação de Mestrado - Escola Superior de Agricultura Luiz de Queiroz, Universidade de São Paulo, Piracicaba.

Dias, M.O.S. 2008. Simulação do processo de produção de etanol a partir do açúcar e do bagaço, visando a integração do processo e a maximização da produção de energia e excedentes do bagaço. 253p. Dissertação (Mestrado em Engenharia Química). Faculdade de Engenharia Química, Universidade Estadual de Campinas.

Fernandes, A.C. 2011. Cálculos na Agroindústria da Cana-de-açúcar. 3ed. Piracicaba: STAB - Sociedade dos Técnicos Açucareiros e Alcooleiros do Brasil. 416p.

Hugot, E. 1986. Handbook of Cane Sugar Engineering. 3ed. Amsterdam: Elsevier. 1166p.

Premalatha, M.; Priya, S.S.; Sivaramakrishnan, V. 2008. Efficient Cogeneration Scheme for Sugar Industry. Journal of Scientific \& Industrial Research 67: 239-242.

Rein, P. 2007. Cane sugar engineering. Berlin, Germany: Verlag Dr. Albert Bartens. 768p.

Seabra, J.E.A. 2008. Avaliação técnico-econômica de opções para o aproveitamento integral da biomassa de cana no Brasil. Tese de Doutorado - Faculdade de Engenharia Mecânica, Universidade Estadual de Campinas, Campinas. 274p. 
Smith, J. M.; Van Ness, H. C.; Abbott, M. M. 2007. Introdução à Termodinâmica da Engenharia Química. 7ed. Tradução de Eduardo Mach Queiroz e Fernando Luiz Pellegrini Pessoa. Rio de Janeiro: LTC. 626p.

Venkatesh, K.S.; Roy, A.S. 2010. Development and Installation of High Pressure Boilers for Co-Generation Plant in Sugar Industries. Smart Grid and Renewable Energy 1: 51-53. 
Cenário 1: Mix de produção para açúcar 35\%

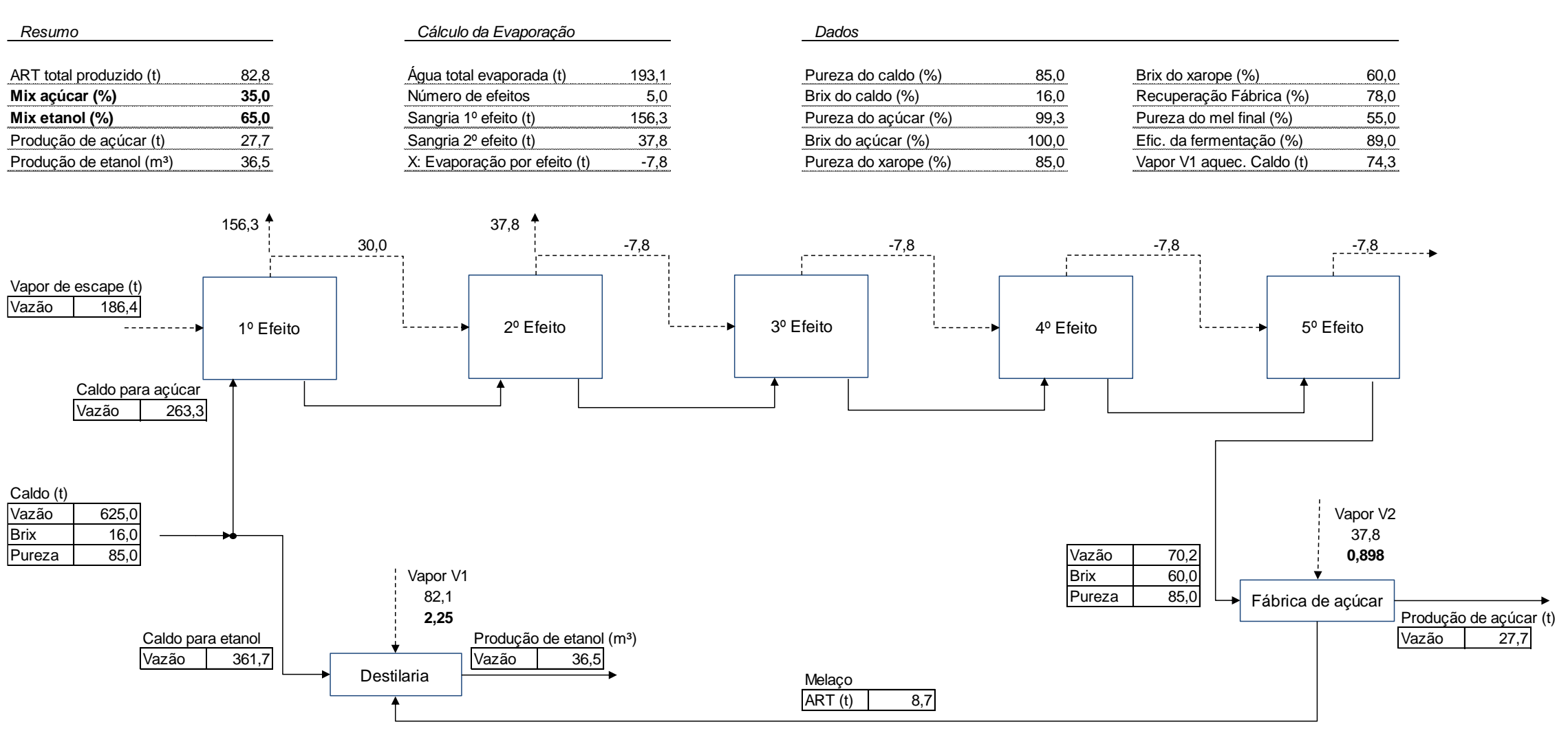

Anexo 1. Cenário de simulação de consumo de vapor com o mix de produção $35 \%$ para açúcar 
Cenário 2: Mix de produção para açúcar 40\%

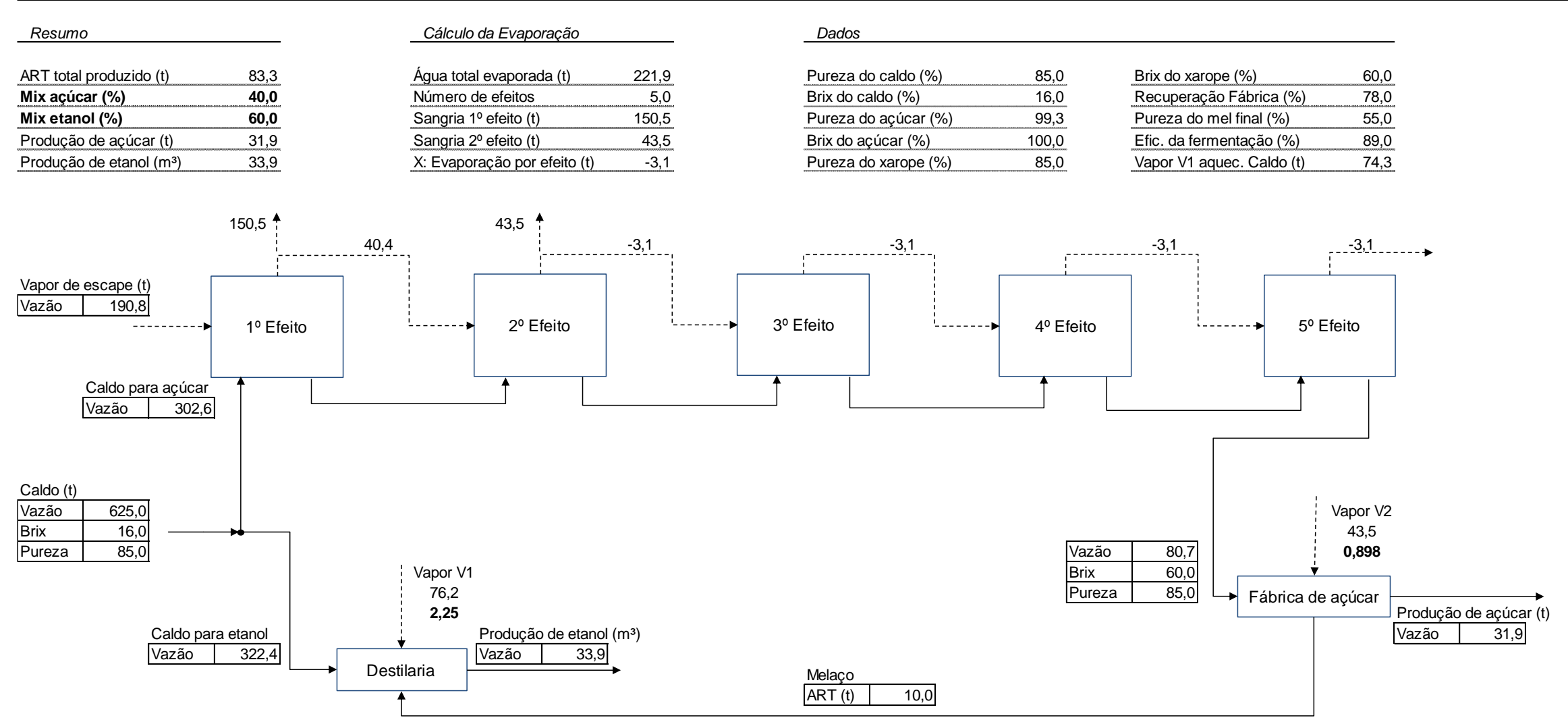

Anexo 2. Cenário de simulação de consumo de vapor com o mix de produção $40 \%$ para açúcar 


\section{Cenário 3: Mix de produção para açúcar $45 \%$}

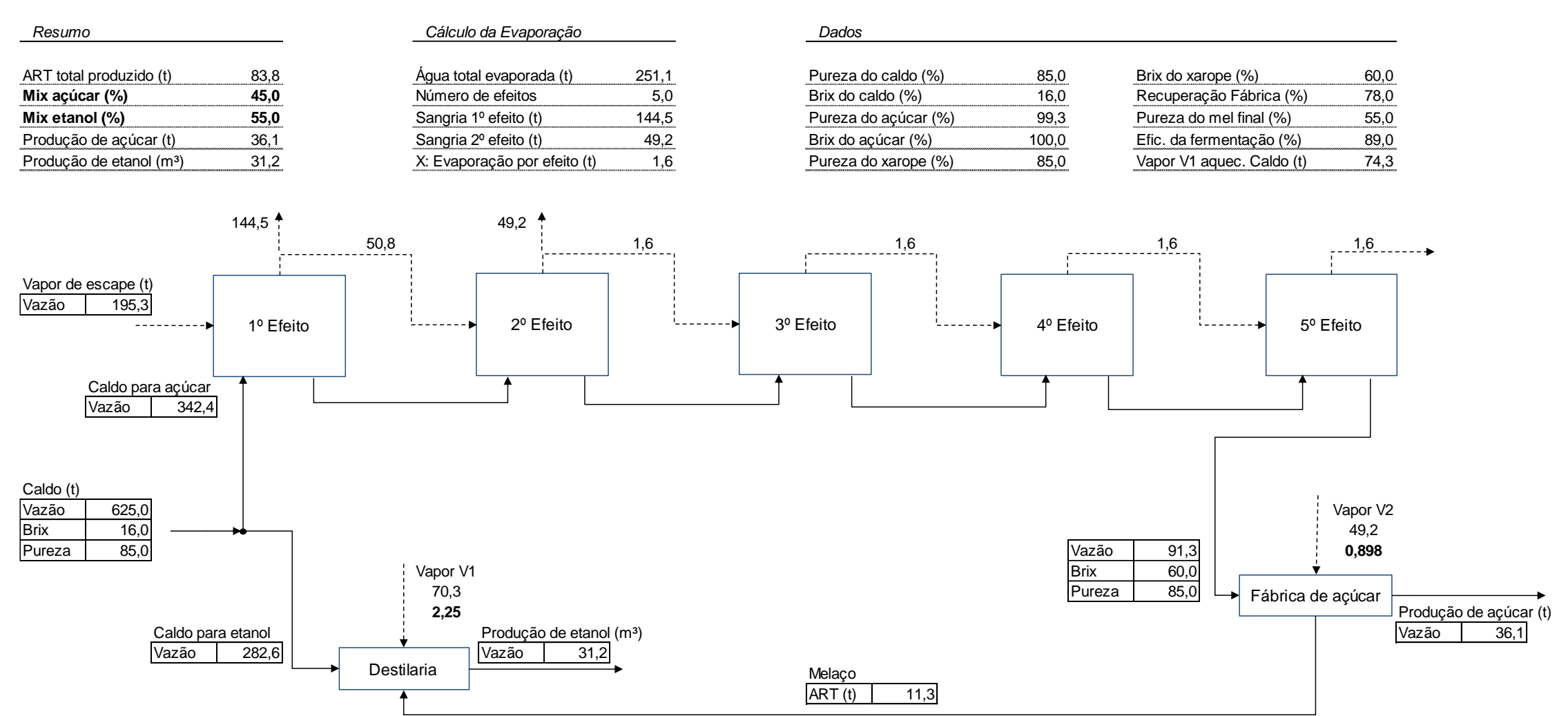

Anexo 3. Cenário de simulação de consumo de vapor com o mix de produção $45 \%$ para açúcar 
Cenário 4: Mix de produção para açúcar 50\%

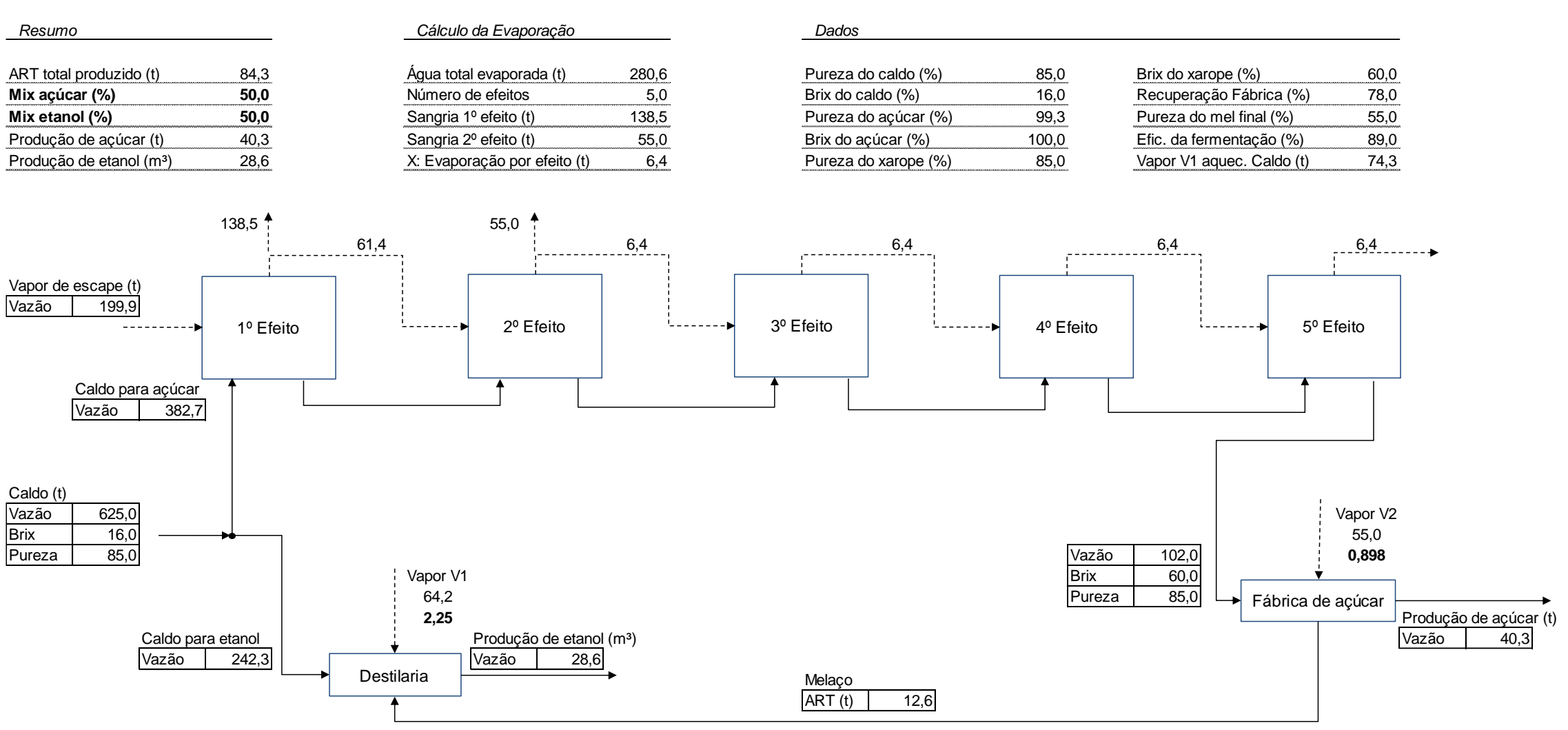

Anexo 4. Cenário de simulação de consumo de vapor com o mix de produção $50 \%$ para açúcar 


\section{Cenário 5: Mix de produção para açúcar 55\%}

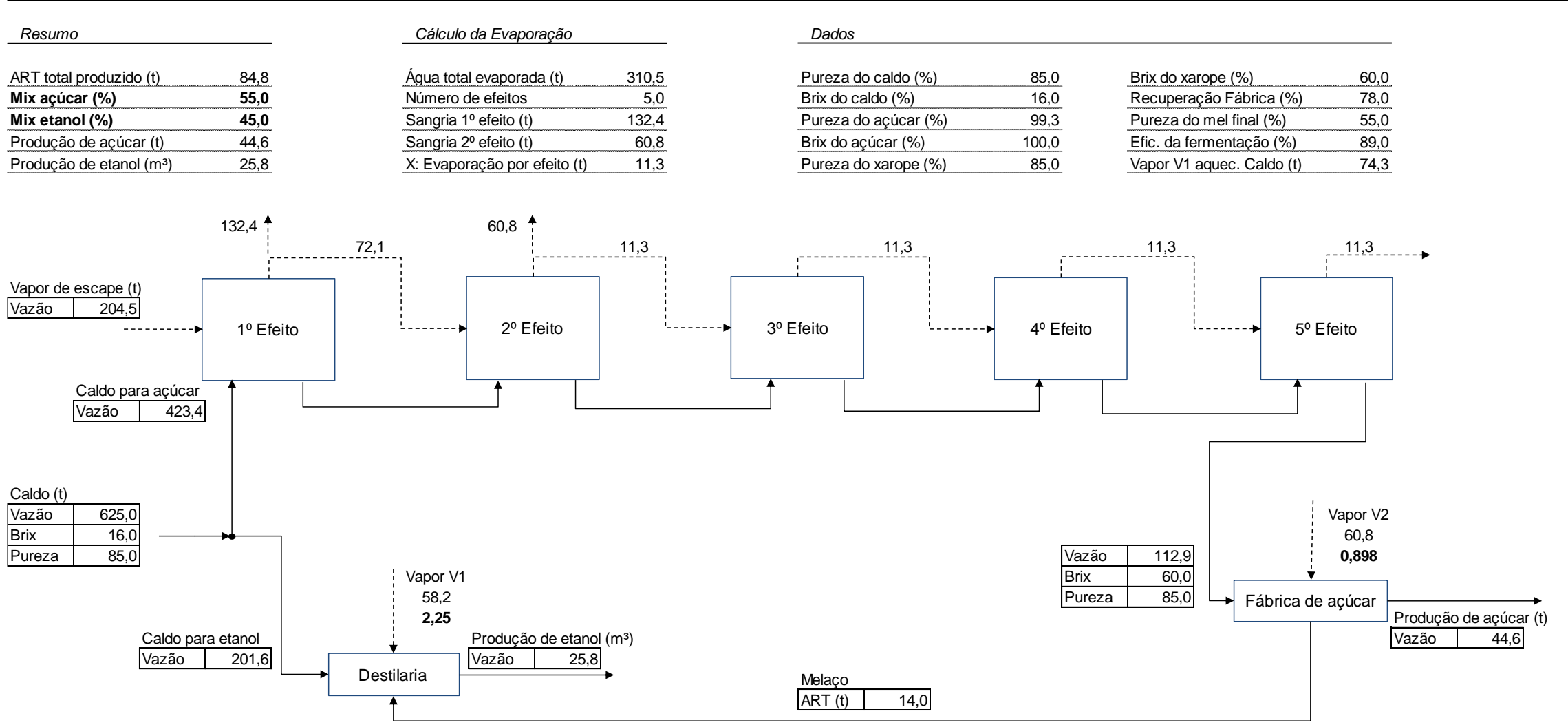

Anexo 5. Cenário de simulação de consumo de vapor com o mix de produção $55 \%$ para açúcar 
Cenário 6: Mix de produção para açúcar 60\%

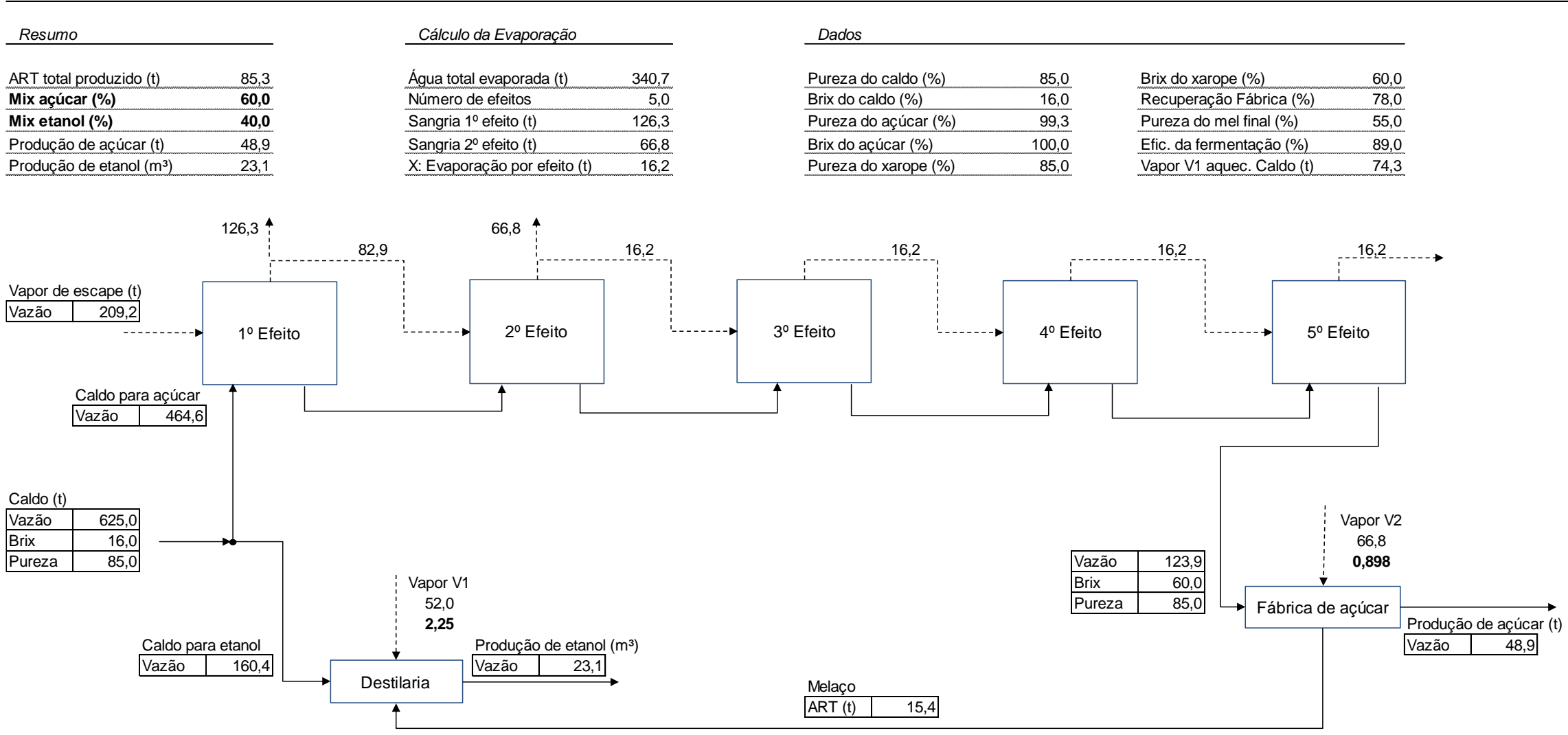

Anexo 6. Cenário de simulação de consumo de vapor com o mix de produção $60 \%$ para açúcar 
Cenário 7: Mix de produção para açúcar $65 \%$

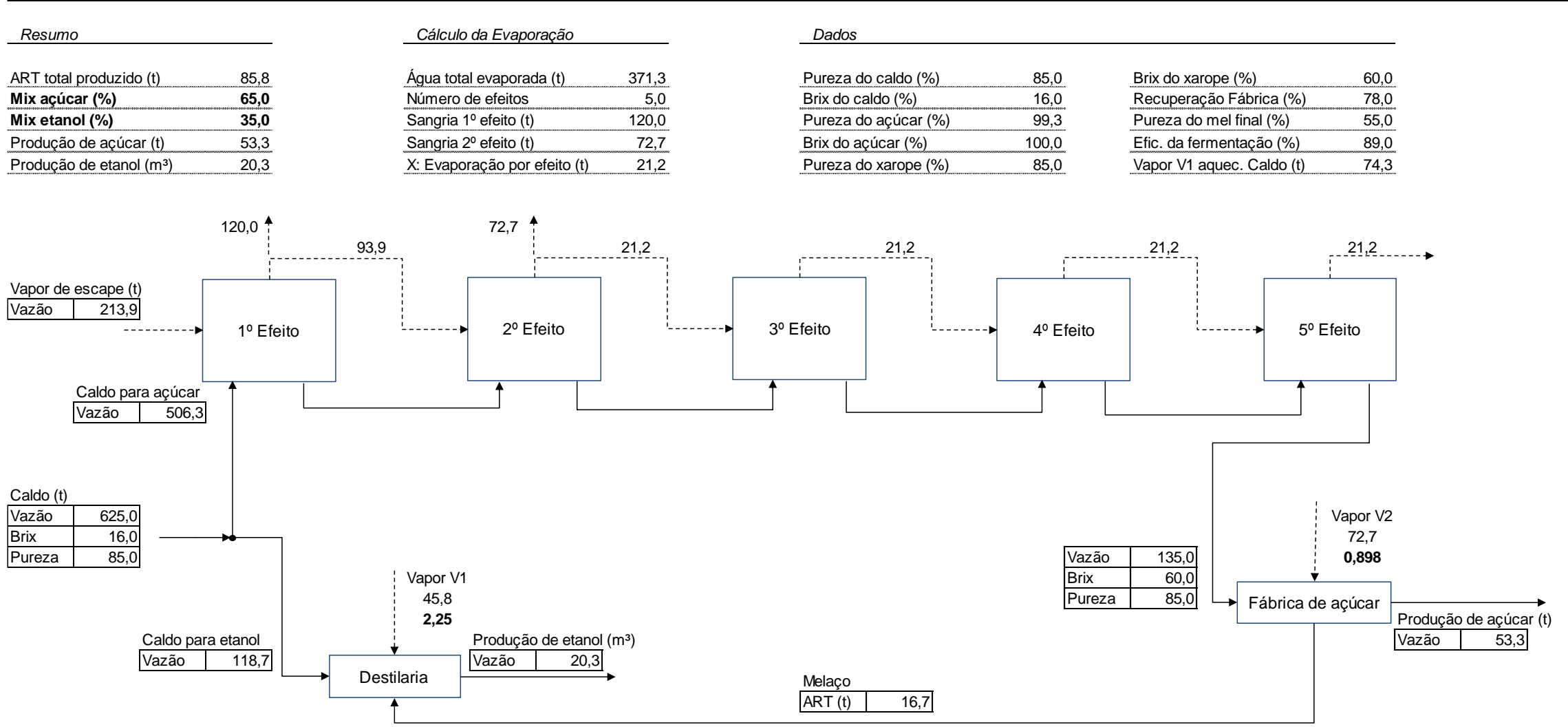

Anexo 7. Cenário de simulação de consumo de vapor com o mix de produção 65\% para açúcar 


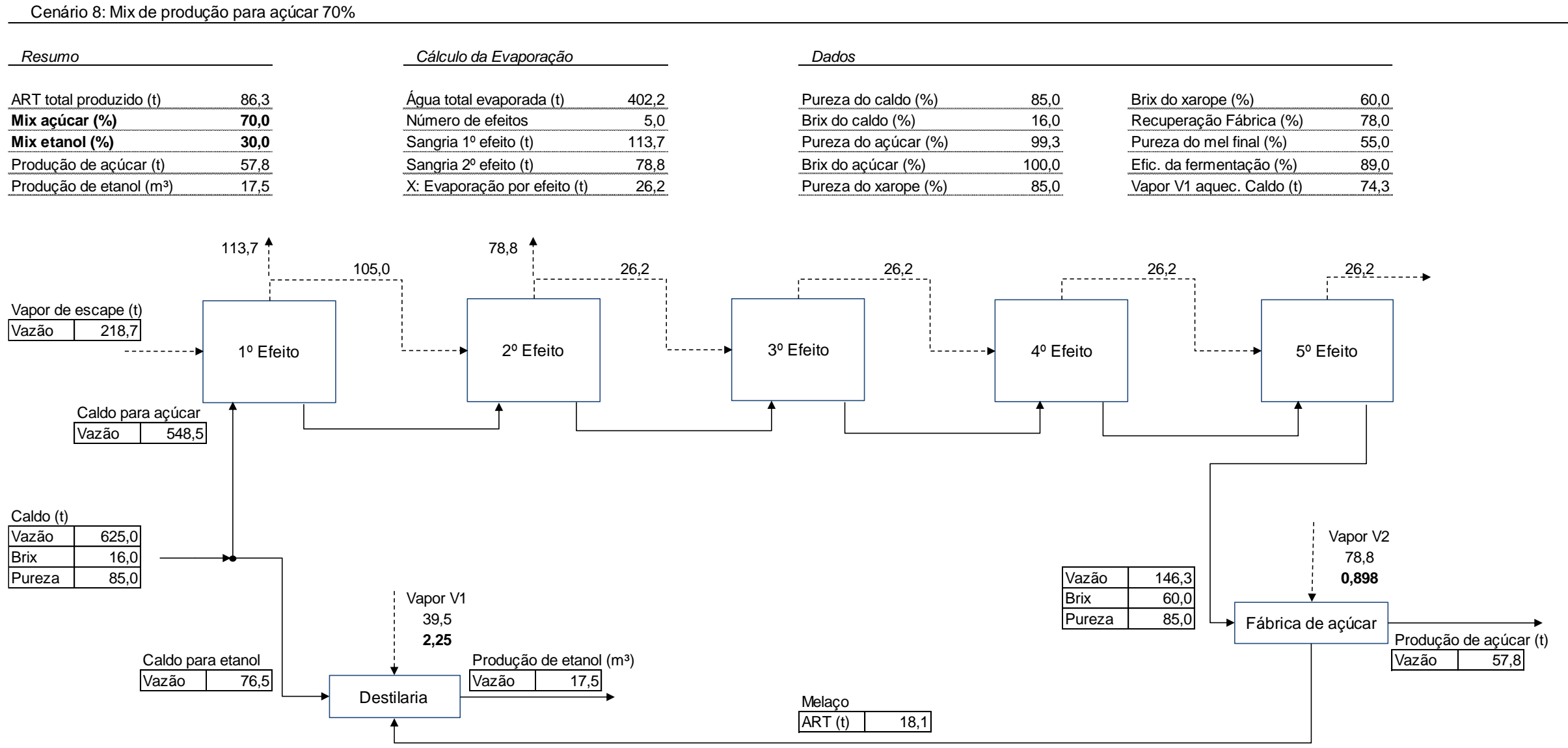

Anexo 8. Cenário de simulação de consumo de vapor com o mix de produção 70\% para açúcar 
Cenário 9: Mix de produção para açúcar $75 \%$

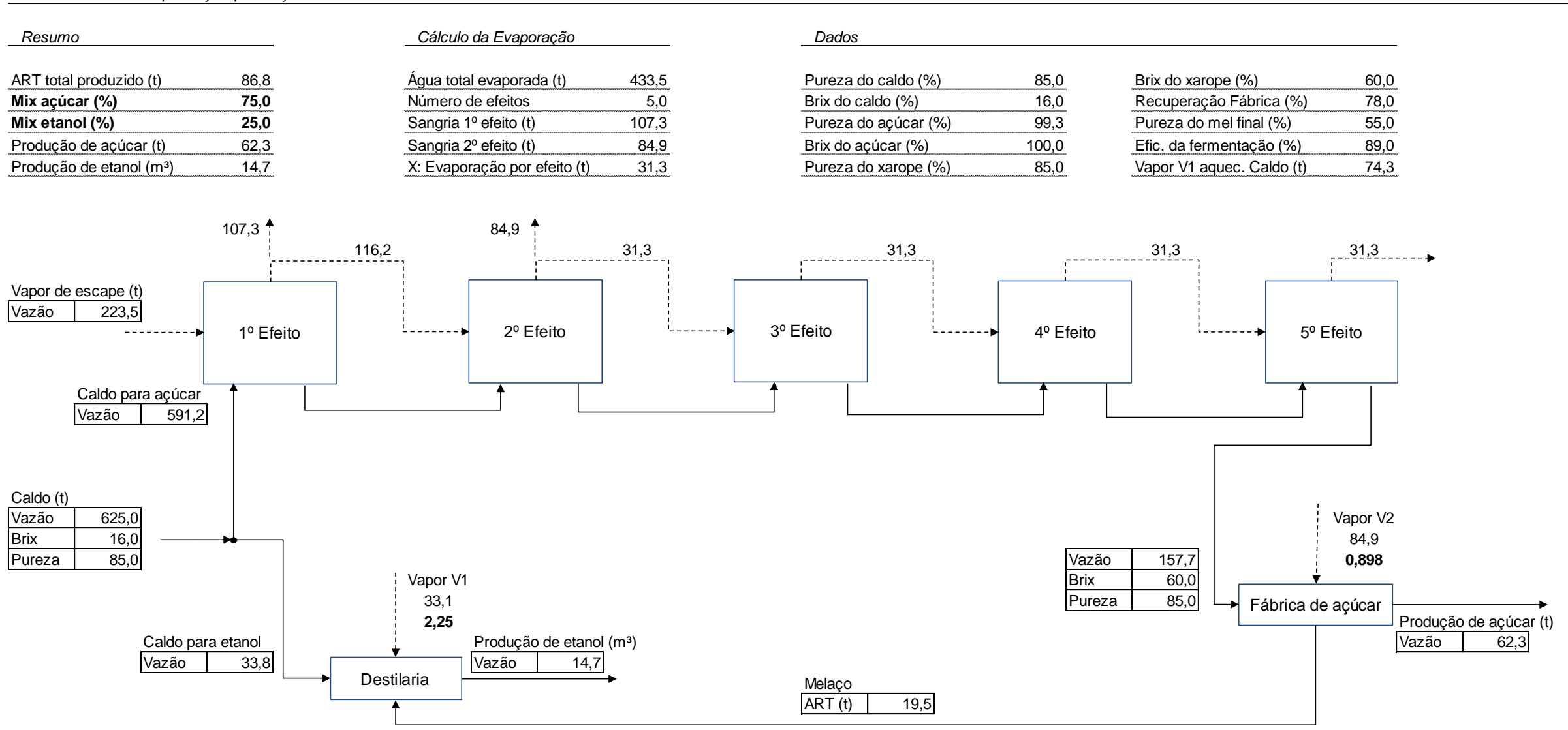

Anexo 9. Cenário de simulação de consumo de vapor com o mix de produção $75 \%$ para açúcar 
Cenário 10: Mix de produção para açúcar 78,9\% (todo caldo enviado para fábrica)

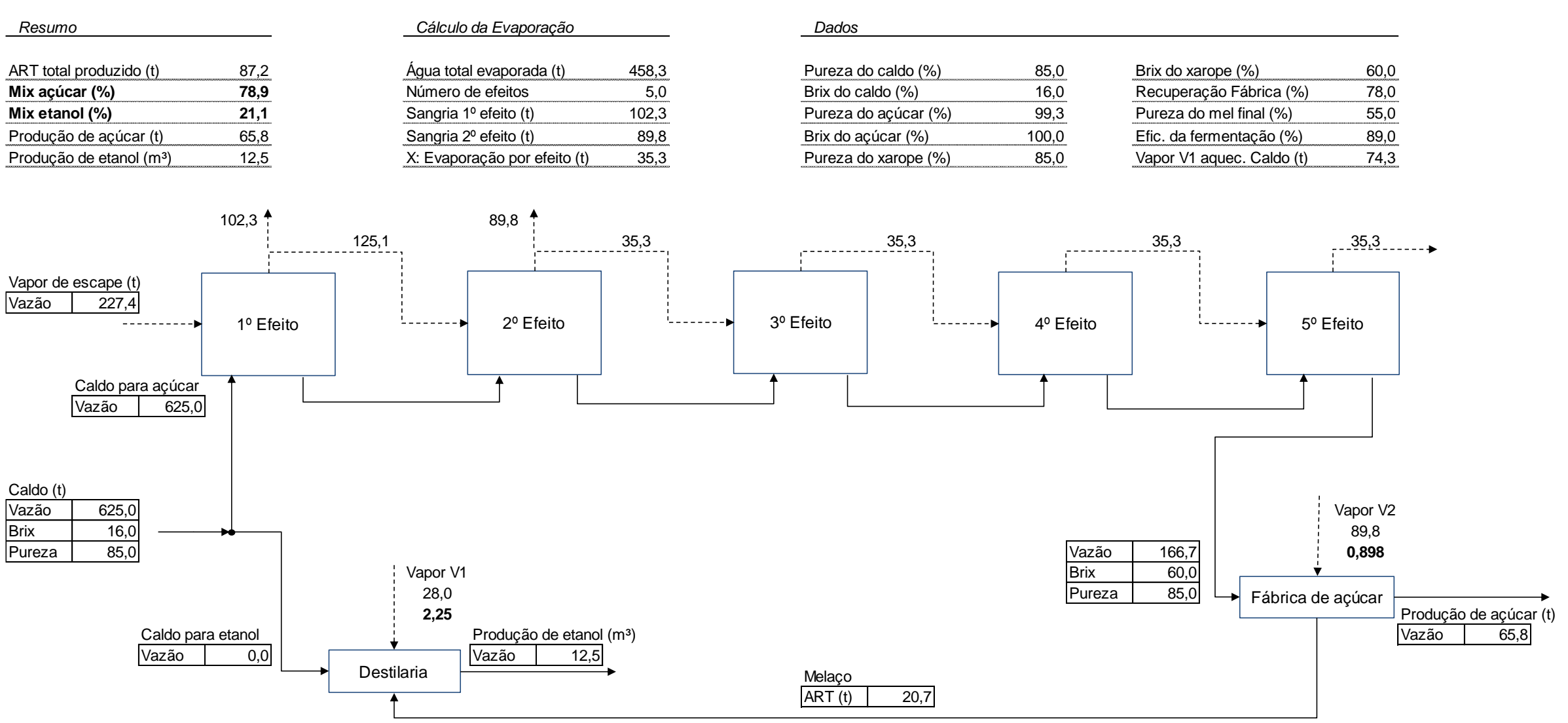

Anexo 10. Cenário de simulação de consumo de vapor com o mix de produção 78,9\% para açúcar 